Trinity University

Digital Commons @ Trinity

Health Care Administration Faculty Research

Health Care Administration

3-2009

\title{
Does Public or Not-for-Profit Status Affect the Earnings of Hospital Workers?
}

Edward J. Schumacher

TrinityUniversity, eschumac@trinity.edu

Follow this and additional works at: https://digitalcommons.trinity.edu/hca_faculty

Part of the Medicine and Health Sciences Commons

\section{Repository Citation}

Schumacher, E.J. (2009). Does public or not-for-profit status affect the earnings of hospital workers? Journal of Labor Research, 30(1), 9-34. doi: 10.1007/s12122-008-9051-4

This Article is brought to you for free and open access by the Health Care Administration at Digital Commons @ Trinity. It has been accepted for inclusion in Health Care Administration Faculty Research by an authorized administrator of Digital Commons @ Trinity. For more information, please contact jcostanz@trinity.edu. 


\title{
Does Public or Not-for-Profit Status Affect the Earnings of Hospital Workers?
}

\author{
Edward J. Schumacher
}

Published online: 12 August 2008

(C) Springer Science + Business Media, LLC 2008

\begin{abstract}
This paper examines the earnings differentials among hospital workers in the public, private nonprofit, and private for-profit sectors. Utilizing data from the 1995 through 2007 Current Population Surveys, unadjusted earnings are highest in the private nonprofit sector and lowest in private for-profit firms. Once measurable characteristics are accounted for, health practitioners in for-profit and nonprofit hospitals earn similar wages while public sector workers earn small but significant wage penalties. Nonprofit hospitals tend to attract workers with higher levels of skill as measured by schooling and potential experience. This could be explained in part by worker sorting and lower cost containment incentives in nonprofit hospitals. Wage change analysis using pooled 2-year panels constructed from the CPS indicate no significant differences in earnings between the three sectors of employment. Whatever the role of the sector of employment on the overall earnings of hospital workers, there is sufficient worker mobility within the industry to largely eliminate systematic wage differences across type of hospital.
\end{abstract}

Keywords Hospital workers $\cdot$ Public status $\cdot$ Not-for-profit status

\section{Introduction}

The health care industry is a unique industry in the US economy and accounts for a large and growing proportion of its resources. Expenditures in 2006 were \$2.11 trillion or $\$ 7,026$ per capita, and accounted for $16 \%$ of GDP. ${ }^{1}$ Healthcare was the largest industry in the USA in 2006 accounting for 14 million jobs, and is expected to generate 3 million new wage and salary jobs between 2006 and 2016. ${ }^{2}$ This industry is unique, in part, due to the fact that the public sector, the for-profit, and

\footnotetext{
${ }_{1}^{1}$ http://www.cms.hhs.gov/NationalHealthExpendData/downloads/tables.pdf.

${ }^{2}$ http://www.bls.gov/oco/cg/cgs035.htm.

E. J. Schumacher $(\bowtie)$

Departments of Healthcare Administration and Economics, Trinity University, San Antonio,

TX 78212, USA

e-mail: Edward.Schumacher@trinity.edu
} 
private not-for-profit sectors all compete directly in the same markets. There has been considerable research examining the theory and outcomes of the differing incentives of these sectors on output markets (Lakdawalla and Philipson 2006; Chakravarty et al. 2005; Horwitz 2005; Sloan 2000; Frank and Salkever 1994; Hoerger 1991), but little work on labor market outcomes. Sloan and Steinwald (1980) use data from the 1970s and find no significant wage differences in wage rates paid by hospitals of different ownership types. Other than this dated study, however, there has been little research examining how labor market outcomes are different within these sectors of the industry.

Previous research on public/private wage differences tends to find moderate to large wage premium for federal government workers (on the order of 10-20\%), with larger differentials for females than for males and for nonwhite males than for white males, and small premiums associated with state and local employees. These differentials, however, are reduced substantially (or even disappear) once occupation is controlled for in detail (Moulton 1990). ${ }^{3}$ These economy-wide studies generally assume, however, that jobs and probability of promotion are similar across sectors, which is generally not the case. Thus, prior studies finding a non-profit or public wage effect are not comparing truly similar jobs.

This paper focuses on wage differentials between workers in public, private notfor-profit, and private for-profit hospitals. Focusing on hospitals in particular is interesting for a number of reasons. First, the large IO literature tends to find a high degree of similarity between for profit and private not-for profit hospitals despite their very different ownership structures, while public hospitals tend to look very different in terms of the amount of uncompensated care, the types of patients served, affiliation with a medical school. Thus, does it follow that the workers in private forprofit and not-for-profit hospitals are similar in their characteristics? Likewise, how do public sector hospital workers differ? Second, given that previous literature examining public/private wage differences have faced difficulty comparing the wages in similar jobs across the different sectors, examining hospital workers will provide a more direct test by comparing workers doing highly similar jobs in the same industry, yet differing in their ownership structure.

The findings of the paper show that for registered nurses, wages are highly similar across all three types of hospitals, but for other workers wages are highest in private nonprofit hospitals and public hospitals' wages tend to be slightly higher than those in private for-profit hospitals. These higher wages are due, however, in large part to nonprofit hospitals attracting workers with higher skill levels and once measured characteristics are accounted for there is only a small positive wage differential for nonprofit hospitals over for-profit hospitals and a small negative wage differential is associated with public sector employment. The next section lays out a framework for why wages may differ for workers across the different sectors and briefly examines the previous literature on public/private and for-profit not-for-profit wage differences. "Data and Descriptive Statistics" describes the data and provides some descriptive statistics, while "Cross-sectional Estimates of Public/Nonprofit/for-Profit

\footnotetext{
${ }^{3}$ Postal workers are the exception (Hirsch et al. 1999).
} 
Wage Differentials Within the Hospital Industry" shows cross sectional regression results. In "Longitudinal Estimates of the Public/Nonprofit/for-Profit Wage Differentials in Hospitals" wage change regressions are presented using 2-year matched panels, and "Conclusion" provides conclusions.

\section{Why Might Wages Differ Across Sectors?}

\section{Compensating Differentials and Skill Differences}

If hospital workers had similar skills and preferences, all hospital jobs were equally attractive, and hospital types competed in the same labor market, wages would equalize across hospital type. That is, the law of one price predicts that workers would move to where wages were higher, all things equal, and eliminate any shortrun wage difference that existed. Long-run equilibrium wage differentials would arise, however, to the extent that there are unmeasured differences in skills, preferences, or working conditions across sectors.

One of the main rationales for the existence of private not-for-profit firms is that they are a response to contract failure that arises from the uncertainty of identifying quality of care. Since nonprofits are barred from distributing net earnings, Easly and O'Hara (1983) and Handy and Katz (1998) argue that nonprofits will be prevalent in markets where consumers lack information about the good (price, quality, quantity, etc.) since nonprofits will help alleviate the consumer trust problem. Managers may have less incentive to hold down wages since they do not gain from the resulting cost savings, and thus workers in not-for-profit firms may receive higher wages. To the extent, however, that these higher wages attract a surplus of applicants, firms may respond by selecting higher ability workers. If this ability is not captured by human capital measures typically found in wage studies such as schooling and experience, then a differential may persist.

At the same time though, not-for-profit firms may attract workers who are supportive of the cause of the organization and so may be willing to work for lower wages as a way of donating to a worthy cause. Rose-Ackerman (1996) observes that nonprofit entrepreneurship is ideological in nature and ideological founders will seek out and hire managers and employees who share their vision. The lack of a residual claimant signals to employees that the firm is not profiting from their efforts and thus, they may be willing to accept lower levels of pay in return for greater certainty that their efforts are furthering their altruistic goals. In this case the differential would not be a compensating wage differential but would be due to differences in worker characteristics (though these characteristics are not likely to be measurable by the researchers). Even absent ideology, however, workers may be willing to accept lower pay in nonprofit hospitals if these organizations are able to offer more pleasant working conditions through less financial pressure or greater organizational slack. Thus there may be some compensating differential associated with for-profit hospitals. ${ }^{4}$

\footnotetext{
${ }^{4}$ Lakdawalla and Philipson (1997) suggest that nonprofits are likely to be concentrated in more competitive and less profitable industries and this should put additional downward pressure on wages. To the extent that for-profit and non-profit hospitals are competing in the same output market, however, this should imply equal wages across workers within the industry.
} 
With respect to public sector employment, the literature tends to focus on the question of whether compensation among federal, state and local workers is comparable to similar workers in the private sector. Public sector compensation is determined by some combination of market forces and the interpretation of comparability statutes through the political process, while private sector wages will tend to be determined primarily through market forces. Given the similarity of work across public and private hospitals, we might expect wages to equalize across sectors for most occupations. There may be equilibrium differences, however, if working conditions or other attributes of the job are different. If a hospital is designated as a teaching hospital (affiliation with a medical school and providing the means for medical education to students, interns, etc.), then workers there may be involved with more demanding case loads requiring higher skilled workers. At the same time, however, if workers are able to obtain a higher degree of onthe-job training in teaching hospitals than in non-teaching hospitals, then workers may be willing to accept lower wages in these hospitals to receive this training. The data utilized in this study do not identify teaching hospitals, but teaching hospitals tend to be primarily public or non-profit hospitals, and so this may contribute to both differentials. Public sector employment could offer other job amenities such as greater job security, more regular hours, or other nonwage attributes that workers are willing to pay for in the form of lower wages. Also, similar to the private nonprofit sector, since public sector hospitals tend to have a much higher proportion of uncompensated care (both bad debt and charity care) than do private sector hospitals, it could be that public hospitals attract workers who are also more willing to "donate" a portion of their wage to help fulfill the mission of the organization.

Belman and Heywood (2004) examine the "positions" vs. "people" problem in estimating the public/private wage differential. They first examine the differential when restricting the data set to include only workers in occupations common to both the public and private sectors, they then estimate the differential restricting the data to occupations unique to each sector. They compare these alternative specifications to an unrestricted specification including all occupations and find that the common occupation specification explains a greater share of the overall differential for federal workers, while the unique occupation specification is more important for the state and local government differential. This implies that the federal wage differential is more about differences in workers while the state and local differential is more related to unique occupations.

In an examination of the private for-profit vs. not-for-profit differential, Ruhm and Borkoski (2003) use data from the 1994-1998 Current Population Surveys and find that weekly wages are about $11 \%$ lower in nonprofit jobs as compared to forprofit jobs, but this is due almost entirely to differences in hours worked and the concentration of nonprofit jobs in low paying industries. Roomkin and Weisbrod (1999) use data from the 1992 Hospital Compensation Survey conducted by Hay Management Consultants and find evidence that top executives in nonprofit hospitals receive lower compensation than those in for-profit hospitals, but there is no difference for middle managers. They also find that the composition of compensation differs across the for-profit and nonprofit sectors. For-profit hospitals are more likely to utilize contingent components to compensation. They conclude that this is consistent with nonprofit and for-profit hospitals having different goals and, therefore, selecting different types of managers. 
Non-competitive Markets

An alternative explanation for wage differentials across sectors is due to limited mobility of workers. If hospitals have market power in some markets but not in others, and workers are not sufficiently mobile then wages may differ across sectors to the extent that hospitals react differently to their market power depending on ownership status. If market power is correlated with ownership type (for example, if public hospitals tend to be in smaller less competitive markets) or if hospitals respond to monopsony power differently (for example, if for-profit hospitals are more likely to act on monopsony) then in highly concentrated markets, wages may differ across sector more than they would in less concentrated markets. To the extent that workers are mobile across sectors, however, wages should equalize within markets and monopsony power would result in wage differentials across market, but not based on sector.

Hirsch and Schumacher (1995 and 2005) examine the monopsony hypothesis among nurses. They find no long run evidence that relative nursing wages are affected by hospital market structure. They do find, however, that when there is an increase in hospital market concentration, there is a small reduction in $\mathrm{RN}$ wages. They interpret this as being consistent with short-run monopsony power, but given the lack of a differential in any of their cross-sectional results, they conclude there is little evidence to support monopsony power in the nursing labor market. Currie et al. (2005) examine the effect of market consolidation in California hospitals in the 1990s. They find that while wages were not significantly affected, there was an increase in the level of effort (number of patients per nurse), which is consistent with monopsony. They find increases in employment, however, and conclude that their results are more consistent with a contracting model than with monopsony or the standard competitive model. Thus, while there are hospitals that may face upward sloping supply curves (Sullivan 1989), there is little evidence that this results in wage differences based on market structure.

With the exception of Roomkin and Weisbrod (1999), which focused specifically on managerial compensation, previous studies examining either the public vs. private wage differential or the for-profit vs. not-for-profit wage differential have faced the difficulty of comparing similar workers doing similar jobs. This paper focuses specifically on occupations within the hospital industry since it has the unique characteristic of containing large segments of public, private for-profit, and private nonprofit employers and workers who are performing similar tasks across sectors. Data from the Current Population Survey are utilized to analyze how wages and employment differ across the three sectors of the industry. Using both cross-sectional data as well as pooled 2-year panels, wage differentials between public, private forprofit and private nonprofit workers in the healthcare industry are estimated.

\section{Data and Descriptive Statistics}

Data

The primary data for this study are drawn from the monthly Current Population Survey (CPS) Outgoing Rotation Group (ORG) earnings files for September 1995 
through June 2007. Beginning in 1994 the CPS began collecting information on the profit status of the employer of workers in the private sector. Previous surveys contain information about public sector workers (federal, state, or local government), but 1994 was the first year they separated private for-profit from private nonprofit employers.

A large number of respondents (20-30\%) have their earnings imputed by the census based on a cell hot-deck procedure in which nonrespondents are allocated the earnings of a "donor" with an identical set of match characteristics. CPS imputation rates have been particularly large in recent years. Imputed earners are excluded from the sample since their inclusion may result in match bias (Hirsch and Schumacher 2004). Since non-responding workers are not in general matched to the earnings of workers in similar settings (industry and sector of employment are not a match criteria), wage differences between public, private for-profit, and private not-forprofit workers are biased toward zero. ${ }^{5}$ Allocated earners cannot be reliably identified in the CPS ORG files between January 1994 and August 1995, but there are reliable allocation codes for September 1995 forward. Thus the sample begins with September 1995 and eliminates workers with allocated earners. About $28 \%$ of the 1995 to 2007 CPS sample is lost due to imputed earnings with an increasing trend in the non-response rate. Nonprofit hospital workers have the highest imputation rate at about $30 \%$, while private for-profit hospital workers have about $23 \%$ who do not report earnings.

The focus is on hospital workers. First, since there is a large literature on output differences between public, private for-profit, and private not-for-profit hospitals, it is also of interest to know if there are labor market differences across hospital types as well. Secondly, focusing specifically on hospitals allows a comparison of workers in a similar employment setting but with different ownership type. In order to make more detailed comparisons, the hospital sample is broken into four groups. Registered nurses (RNs) are examined separately since they make up the largest occupation in health care and perform job duties that are likely to be highly similar across sector of employment. The other three groups are health practitioner occupations other than RNs, ${ }^{6}$ those non-practitioners with at least a college degree, and those non-practitioners with less than a college education.

The samples include employed wage and salary workers ages 18 and over, with positive weekly earnings and hours. The wage on the primary job is measured

\footnotetext{
${ }^{5}$ For example, the finding of Ruhm and Borkoski (2003) of an $11 \%$ lower wage for workers in private not-for-profit settings relative to private for-profit settings is likely to be biased towards zero since some workers in not-for-profit jobs are matched to workers in for-profit jobs and vise versa. The size of the attenuation can be approximated by the proportion of workers with imputed earnings.

${ }^{6}$ Other practitioners include the following. For 1995-2002: Health Diagnosing Occupations (excluding RNs, physicians, dentists, and veterinarians), and Health Assessment and Treating Occupations. For 2003-2007: Health Practitioner and Technical Occupations (excluding RNs, physicians, dentists, and veterinarians). In January 2003, the CPS adopted the 2002 Census industry and occupational classification systems derived from the 2002 North American Industry Classification System and the 2000 Standard Occupational Classification system. The industry changes did not substantially affect the definition of the hospital industry, but there were numerous occupational changes that affected the classification of practitioners. It is not possible to construct time consistent occupational codes to cover the period. Data from the Bureau of Labor Statistics' Occupational Employment Statistics (OES) shows a similar percentage changes in employment over the period for health practitioners as a whole. See http://www.bls.gov/oes/
} 
directly for workers reporting hourly earnings who do not receive tips, commissions, or overtime. For others the wage is calculated by dividing usual weekly earnings on the primary job (which includes usual tips, commissions, and overtime) by usual hours worked per week. ${ }^{7}$ Usual weekly earnings are top-coded at $\$ 1,923$ through 1997 and at $\$ 2,885$ beginning in 1998 . Those at the cap are assigned mean earnings above the cap based on year and gender-specific estimates that assume a Pareto distribution for earnings beyond the median. ${ }^{8}$ Workers with measured hourly earnings less than $\$ 3$ or greater than $\$ 150$ (in 2006 dollars) are omitted.

Following the above sample restrictions, the sample sizes of RNs, other health practitioners, non-practitioners with at least a college degree, and non-practitioners with less than a college degree are $16,439,12,877,7,492$, and 23,020 respectively.

\section{Employment and Wage Growth Over the Period}

Table 1 displays employment for hospital workers between the years 1995 through 2007 and the proportion of employment by year in each sector. Overall, the table shows an increase in employment in the industry with a shift away from the public sector towards private sector employment. For RNs though, employment decreased between 2003 and 2006, but then increases in 2007. Public sector employment decreased over the entire period for RNs, other practitioners, and non-practitioners with less than a college degree. Hatch (2004) shows that economy-wide public sector employment growth lagged behind private growth up to the 2001 recession when public employment surged relative to private employment. Practitioner employment increased the most in the private nonprofit sector. Non-practitioner employment follows a similar pattern as practitioner employment with a more rapid growth in the private sector, especially for those with at least a college degree.

One of the major policy changes over the period was the Balanced Budget Act of 1997 and the associated revisions. The BBA which took effect at the beginning of the federal fiscal year of 1999 reduced Medicare payments to hospitals through reductions in the update factors for DRGs and capital payments, reduction in outpatient payment for some services and the establishment of an outpatient DRG system, a reduction in Medicare disproportionate share (DSH) payments, and a reduction in direct and indirect graduate medical education payments. The initial act was expected to reduce reimbursement to hospitals by $\$ 119$ billion between 1998 and 2004 (Lindrooth et al. 2006). Revisions such as the Medicare Balanced Budget Refinement Act of 1999 were estimated to cut this reduction by $\$ 21$ billion.

Lindrooth et al. (2006) examine the effect of the BBA and related revisions on hospital nurse staffing ratios. They create a "financial pressure index" which measures a hospital's dependence on Medicare patients in its total patient mix. Their

\footnotetext{
7 Those reporting "variable" hours have their implicit wage calculated, if necessary, using hours worked last week.

${ }^{8}$ Estimates of gender-specific means above the cap for 1973-2006 are posted by Barry Hirsch and David Macpherson at http://www.unionstats.com. Values are about 1.5 times the cap, with somewhat smaller female than male means and modest growth over time. Over the sample period about $1 \%$ of the sample reports earnings at the cap, and similar proportions of public, non-profit, and for-profit hospital workers report earnings at the cap.
} 


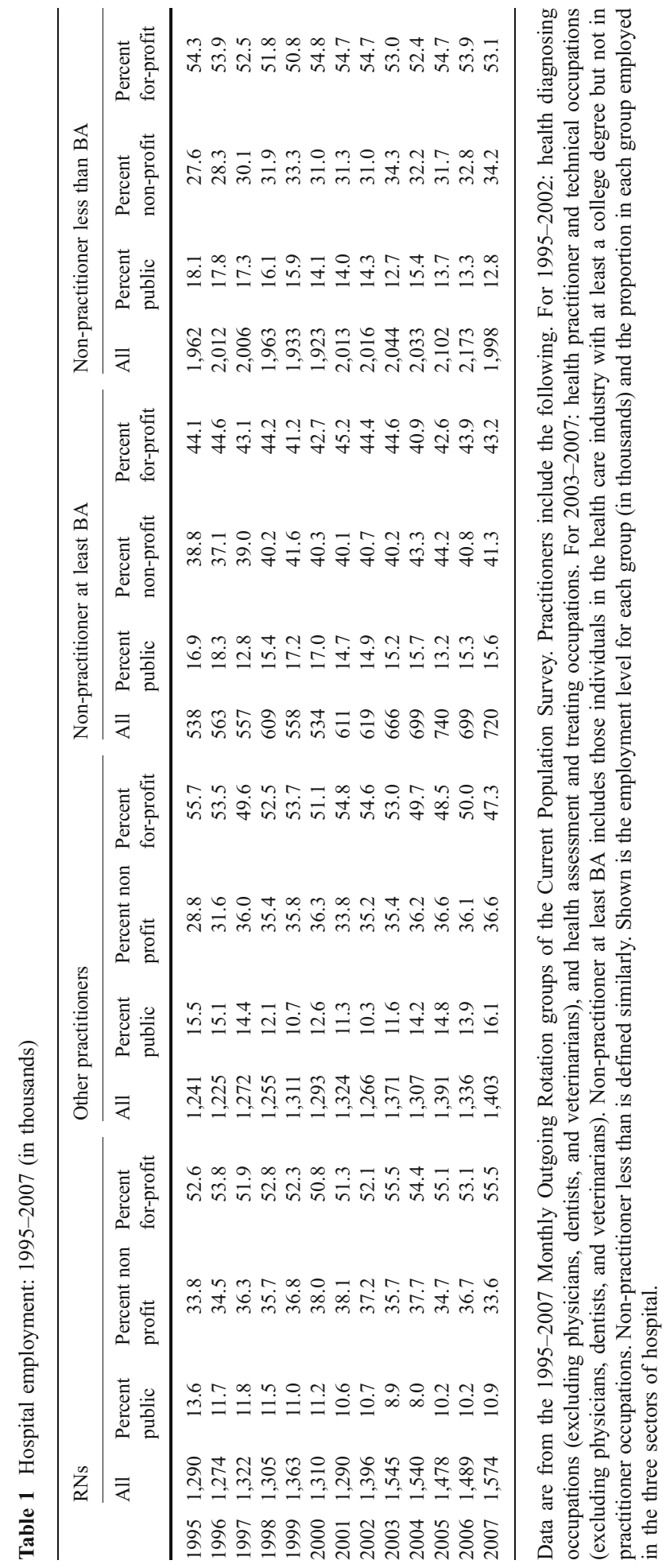


results show that non-safety net hospitals with a high dependence on Medicare revenues have about twice the decline in $\mathrm{RN}$ staffing ratios than do non-safety net hospitals with a low dependence on Medicare revenues. There is not a differential effect on staffing ratios in safety net hospitals.

Zuckerman et al. (2001) explored how safety net hospitals (defined as hospitals with a high share of the uncompensated care market and uncompensated care burden) fared over the 1990s and find that while hospitals with high market share/ high burden lost service volume, they did not reduce staffing levels and expenses at the same rate. Approximately half of safety net hospitals are public hospitals (Lindrooth et al. 2006), thus one might expect public hospital earnings to diminish over this period.

To illustrate relative wage movements during the period, an adjusted wage index is constructed for each group. A separate log wage equation is estimated for each group of hospital workers as well as for workers outside the health industry with and without a college degree. These latter groups are shown in order to make relative wage comparisons. The regressions include controls for years of schooling, experience and its square, and dummy variables for gender, union membership, part-time employment, race (3), marital status (2), region (8), and year. The coefficients from the year dummies are converted to a percentage of the wage in 1995 (the omitted year), which is set equal to 100. Figure 1 displays these indexes, revealing that early in the period, healthcare wages were relatively flat or declining

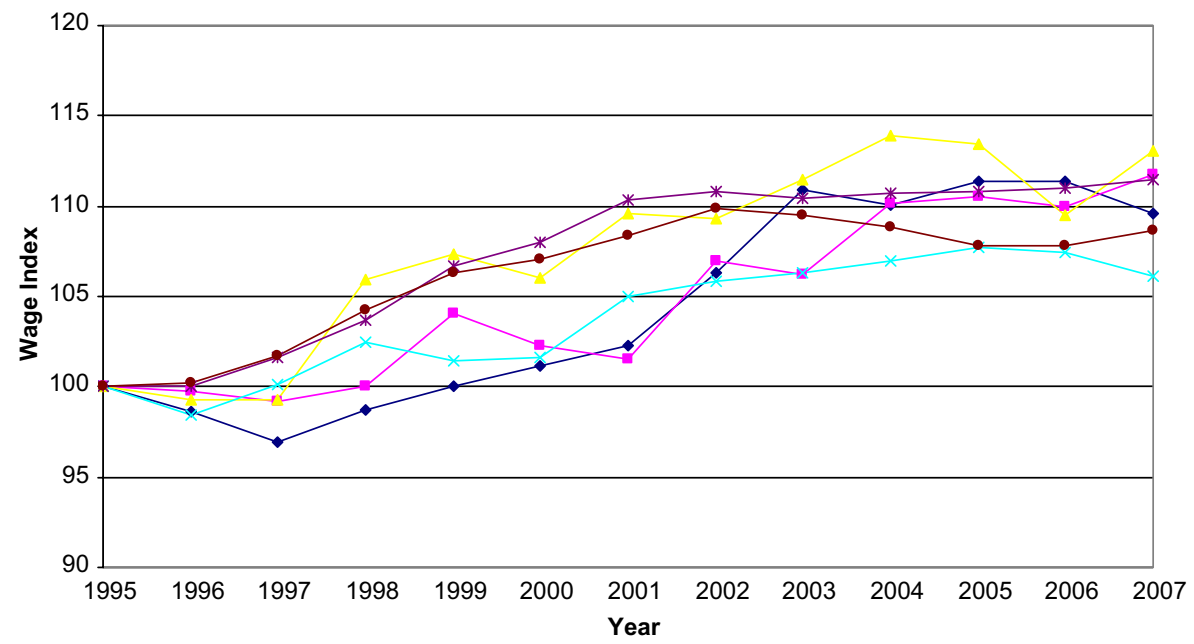

Fig. 1 Wage indices by year by group. Data are from the 1995-2007 Monthly Outgoing Rotation groups of the Current Population Survey. Shown are log wage regression coefficients on year dummies, with $1995=100$ estimated separately for each group. The indices are derived from a separate log wage equation for each group including controls for years of schooling, potential experience (years since finishing school) and its square, and dummies for race (2), gender, part-time status, marital status (2), region (8), large metropolitan area, and year (10). The coefficients on the year dummies are converted to a percentage index by: $\exp (\beta) \times 100$, where $\beta$ is the coefficient 
(especially for nonpractitioners with a college degree). Beginning around 1997, however, wages began rising. Health industry wages flattened out again in the 1999 to 2001 period and then rose rapidly in the 2001 to 2004 period. It appears that wage growth has slowed in the most recent years. Practitioners had particularly rapid wage growth over the 2000 to 2004 period so that a hospital RN in 2004 is estimated to earn about $12 \%$ more than a similar RN in 1995. Overall, wage growth was most rapid for non-practitioners with a college degree.

This pattern in wages roughly follows the rise and subsequent decline of managed care in the health insurance sector. The flat wage and employment growth experienced in the mid 1990s reflects the slowdown in spending over that period due, in part, to the cost containment efforts of managed care. As the influence of manage care waned in the late 1990s and health care spending began to increase more rapidly, health care employment and relative wages followed suit. This pattern seems particularly strong for practitioners relative to non-practitioners in health care. Buerhaus and Staiger (1996) examine the role of managed care on the nursing workforce and find that states with large HMO enrollment experienced slower employment growth and more rapid movement of nurse employment out of the hospital setting. They find smaller effects on RN earnings. Schumacher (2001) examines the role of HMO penetration on explaining the decline in real earnings for RNs in the 1990s. He finds that metropolitan areas with large HMO penetration experienced slightly lower earnings, but this explains only a small portion of the overall decline in earnings. Both studies suggest that to the extent managed care resulted in lower RN earnings, it did so uniformly across all markets.

It is difficult to detect the direct effect of the BBA on hospital earnings from these data as there were multiple factors occurring on both the supply and demand side of the market. Presumably, though the rising real and relative earnings for health care workers over the late 1990s into the early 2000s would have been even larger in the absence of the BBA. Studies by Bazzoli et al. (2004), Lindrooth et al. (2006), and Zuckerman et al. (2001) all show that hospitals responded to the BBA differently depending on the level of financial pressure Medicare changes imposed on them. This implies that hospitals' demand for labor may also have varied over this period. To the extent, however, that workers are mobile across hospitals this would result in a lower overall wage rather than changes in relative wages across hospitals. If workers are not mobile across hospitals, then the BBA may have resulted in growing differentials. It could be, therefore, that there were differential effects on the wage growth of public and private sector hospital workers. This possibility is examined below.

\section{Cross-sectional Estimates of Public/Nonprofit/for-Profit Wage Differentials Within the Hospital Industry}

Table 2 displays descriptive statistics for each of the groups. Overall, unadjusted wages are about $6-8 \%$ higher in the private non-profit sector, although for RNs there is only a $2-3 \%$ difference across sectors. Among other practitioners, workers in the private nonprofit sector earn about $1.9 \%$ higher wages than those in the public sector and $7.8 \%$ higher wages than those in the private for-profit sector. For non- 


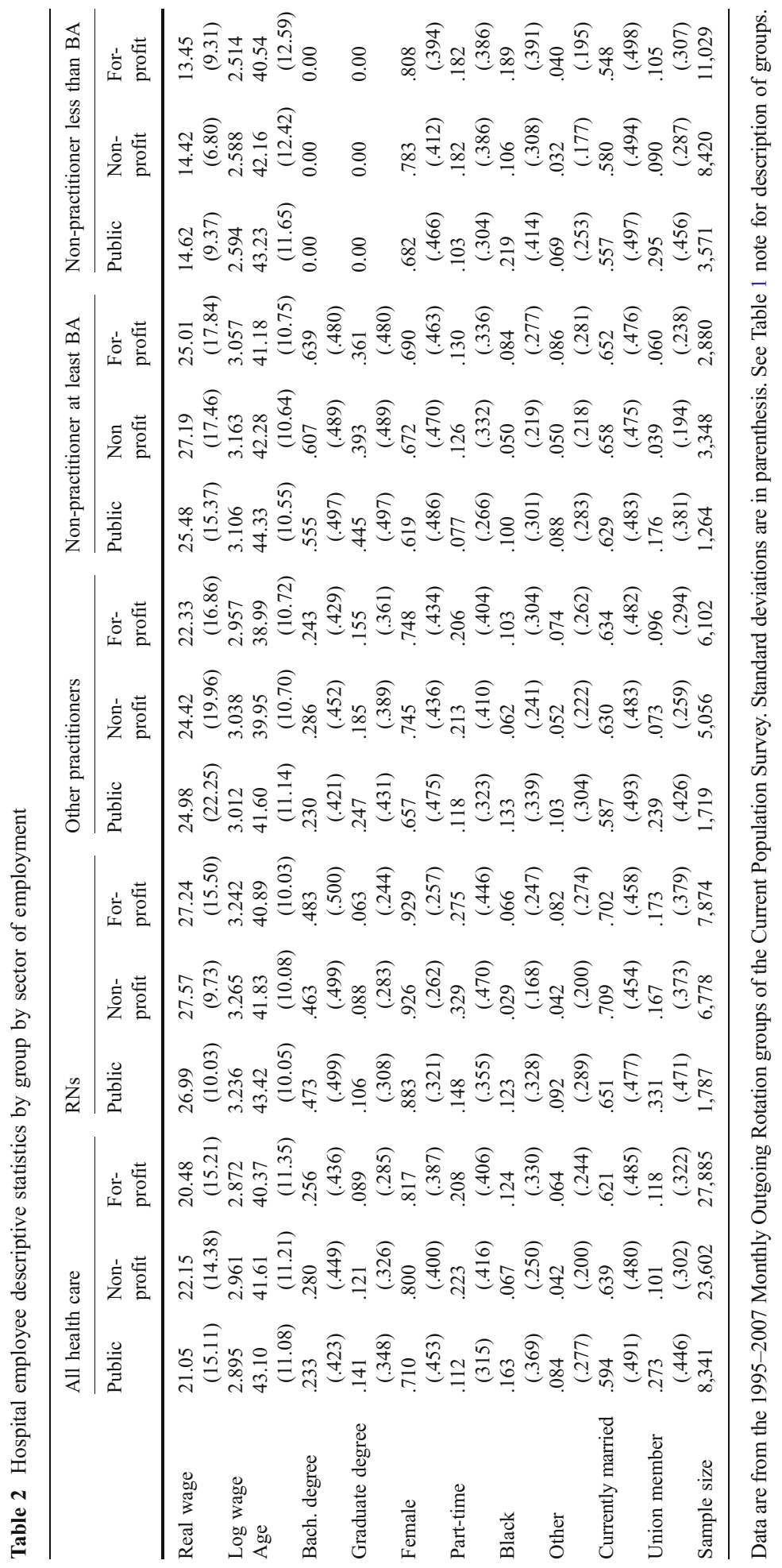


practitioners with a college degree, public sector wages are about 5.2\% lower and for-profit wages are about $9.6 \%$ lower than private nonprofit wages. For those with less than a college degree private nonprofit wages are slightly lower than public wages and are about $7.1 \%$ higher than private for-profit wages. Public sector workers tend to be older, are more likely to hold a graduate degree, are less likely to be white, and more likely to be a union member. This section examines how these differentials are affected by controlling for measurable characteristics.

The estimation begins with a standard cross-sectional log-wage equation:

$$
\ln W_{i t}=\sum_{j=1}^{J} \beta_{j} X_{i j t}+\sum_{y=2}^{Y} \tau_{y} \operatorname{Year}_{i y}+\delta_{1} \text { Public }_{i t}+\delta_{2} \text { PrivateNP }_{i t}+\varepsilon_{i t},
$$

where $\ln W_{\mathrm{i}}$ is the $\log$ of the real (hourly) wage for worker $i$, at time $t, X$ contains $J-1$ personal, job, and labor market characteristics (e.g., education, potential experience, union status, region, etc.) and contains the corresponding coefficients $\left(X_{1}=1\right.$ and $\beta_{1}$ is the intercept). Public is a dummy variable equal to 1 if the worker is employed in the federal, state or local government, and PrivateNP is equal to one if the worker is employed by a private nonprofit firm (with private for-profit as the omitted group). Year includes dummy variables for the years 1996-2007. For now $e_{\mathrm{i}}$ is assumed to be a well behaved error term. The coefficients $\delta_{1}$ and $\delta_{2}$ are the adjusted log earnings differences relative to the for-profit sector. That is, $\delta_{2}$ is an estimate of the wage differential between private for-profit and nonprofit workers, holding all other variables constant, and $\delta_{1}$ is the unbiased differential between public sector workers and private for-profit workers.

Table 3 shows estimates of these differentials, pooled over the years 1995 to 2007. Other than the variables shown in the table, dummy variables for year (12), and region (8) are included in the model. There is a negative and significant differential associated with employment in the public sector. Overall, health industry workers in public employment earn about $2.1 \%$ lower wages than similar workers employed in the private for-profit sector, and $4.6 \%$ less than workers in private nonprofit hospitals. For RNs, the differentials are only about $1.5 \%$ and $2.5 \%$ while for other practitioners the differential is about $1.3 \%$ between public and private for-profit and about 3.9\% between public and non-profit hospital workers. For nonpractitioners wages are lowest in the private for-profit sector. Non-practitioners with at least a college degree earn about $6.8 \%$ more in the private nonprofit sector over private for-profit jobs, while nonpractitioners without a college degree earn about $3 \%$ more in the private for-profit sector than in either the public or not-for-profit sector.

Among the other coefficients, there are large returns to education and relatively flat returns to experience among practitioners. There is not a wage differential associated with gender for RNs (where about $94 \%$ are female), but a significantly lower wage for females among other hospital workers. The union wage differential is relatively small within the industry ${ }^{9}$. Among RNs there is a higher wage for parttime employment. This is counter to the other occupations within the industry and to

\footnotetext{
${ }^{9}$ See (Hirsch and Schumacher 1998). The negative differential for non-practitioners with a college degree is likely capturing management positions which should be relatively high wage with little or no unionization.
} 
Table 3 Cross-sectional log wage differentials among hospital workers

\begin{tabular}{|c|c|c|c|c|c|}
\hline & All health care & RNs & $\begin{array}{l}\text { Other } \\
\text { practitioners }\end{array}$ & $\begin{array}{l}\text { Non- } \\
\text { practitioner } \\
\text { at least BA }\end{array}$ & $\begin{array}{l}\text { Non- } \\
\text { practitioner } \\
\text { less than BA }\end{array}$ \\
\hline Public & $-0.021(0.005)$ & $-0.015(0.008)$ & -0.013 & $0.013(0.016)$ & 0.034 \\
\hline Private non-profit & $0.024(0.004)$ & $0.010(0.005)$ & $0.025(0.008)$ & $0.066(0.012)$ & $0.031(0.005)$ \\
\hline Some college & $0.347(0.004)$ & $0.142(0.020)$ & $0.221(0.012)$ & - & $0.181(0.005)$ \\
\hline Bacc degree & $0.645(0.005)$ & $0.226(0.020)$ & $0.492(0.012)$ & - & - \\
\hline Grad degree & $0.838(0.006)$ & $0.327(0.022)$ & $0.764(0.015)$ & $0.289(0.011)$ & - \\
\hline Experience & $0.028(0.001)$ & $0.018(0.001)$ & $0.030(0.001)$ & $0.036(0.002)$ & $0.021(0.001)$ \\
\hline $\operatorname{Exp}^{2} / 100$ & $-0.048(0.004)$ & $-0.029(0.002)$ & $-0.049(0.003)$ & $-0.065(0.004)$ & $-0.033(0.001)$ \\
\hline Female & $-0.047(0.004)$ & $-0.008(0.009)$ & $-0.105(0.009)$ & $-0.124(0.011)$ & $-0.107(0.006)$ \\
\hline Union member & $0.107(0.005)$ & $0.075(0.007)$ & $0.019(0.013)$ & $-0.118(0.021)$ & $0.073(0.007)$ \\
\hline Part-time & .004) & & & $-0.142(0.016)$ & $-0.105(0.006)$ \\
\hline Currently mar & $0.085(0.005)$ & $-0.003(0.008)$ & $0.065(0.010)$ & $0.109(0.014)$ & $0.052(0.007)$ \\
\hline Previously married & $0.034(0.006)$ & $-0.002(0.009)$ & $-0.005(0.010)$ & $0.018(0.019)$ & $0.022(0.008)$ \\
\hline Black & $-0.117(0.006)$ & $-0.039(0.011)$ & $-0.084(0.014)$ & $-0.115(0.021)$ & $-0.073(0.007)$ \\
\hline Other race & $-0.060(0.007)$ & $0.003(0.010)$ & $-0.063(0.016)$ & $-0.159(0.021)$ & $-0.068(0.012)$ \\
\hline Hispanic & $-0.138(0.007)$ & $-0.041(0.015)$ & $-0.077(0.018)$ & $-0.152(0.027)$ & $-0.105(0.008)$ \\
\hline
\end{tabular}

Data are from the 1995-2007 Monthly Outgoing Rotation groups of the Current Population Survey.

Private for-profit is the omitted group. Also included in the model are dummy variables for year (10), and region (8).

results for the economy as a whole where there exist small part time penalties for women and larger penalties for men (Hirsch 2005). This wage advantage for parttime employment could be due to lower non-wage benefits for part-time workers, older workers selecting into part-time jobs, or to differences in shift work. If parttime jobs are more likely to be on weekends or late night shifts and there is a premium for these shifts (as found by Schumacher and Hirsch 1997), then this will show up as an apparent wage advantage.

In order to examine the correlation between sector of employment and the other right-hand-side variables Table 4 shows public and private nonprofit wage differentials under alternative specifications of the model. Line 1 only includes dummy variables for public and nonprofit employment. These differentials are equivalent to the unadjusted wage differences shown in the descriptive statistics in Table 2. Overall, there is a small premium of about $2 \%$ for public sector employment over private for-profit, and relatively large premium of about $9 \%$ for nonprofit over forprofit employment. When union status is added in line 2 the for-profit/nonprofit differential is largely unaffected, but the public wage differential goes to zero. Public sector hospital workers have a much larger union density than private sector workers ( $30 \%$ for public vs. about $10 \%$ for private). Thus, when union is not controlled for, the public dummy is capturing some of the positive union wage effect.

In line 3, dummy variables for schooling achievement, potential experience and its square, and part-time status are added. Note here that there is a large change in the estimated coefficients for public and nonprofit status. For the entire hospital sample, the public wage differential falls from 0.001 to -0.046 , while the nonprofit differential falls from 0.091 to 0.037 . Virtually all the decline is due to the schooling and experience variables as part-time status has little effect on the differentials. 


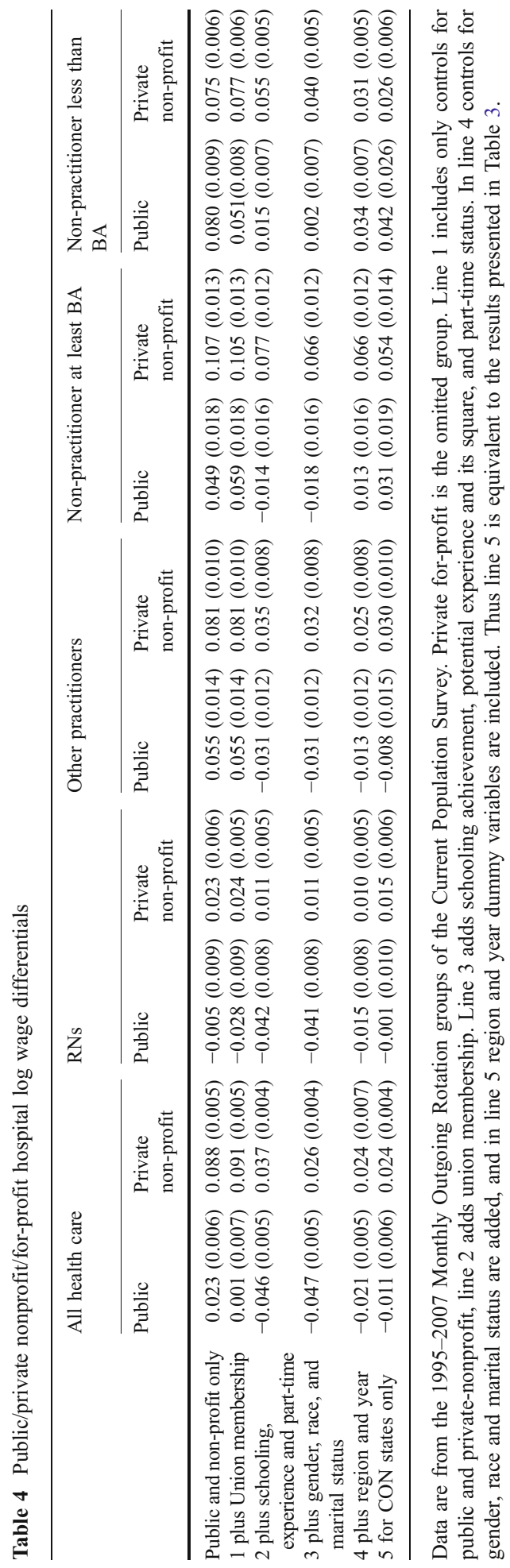


These results imply that a large part of the reason that private nonprofit workers earn higher wages than for-profit workers is that they tend to have higher levels of schooling and experience. Likewise, public sector workers tend to earn similar wages to private sector workers, despite their higher levels of schooling and experience and once these are accounted for there is a wage penalty for public sector employment. This effect is smallest for registered nurses where the inclusion of schooling and experience controls has only a small effect on the public and nonprofit differentials. This suggests that measured skill levels are relatively similar for RNs across sectors while for other hospital workers, those employed in the for profit sector tend to hold lower levels of skill.

Line 4 adds controls for gender, race and marital status, and it shows that these variables have virtually no effect on the public or nonprofit wage differentials. The coefficients on public and nonprofit employment are largely unaffected by the inclusion of these variables for most groups. The one exception may be for nonpractitioners, where there is a slight drop in the nonprofit wage advantage over forprofit workers. But either way, differences in race, gender, or marital status play little to no role in the wage differentials across sectors of employment. Line 5 adds region and year dummies, so that the results in this row are identical to those presented in Table 3. Here we see that the negative public sector differentials become somewhat smaller-it is cut in approximately half for most of the groups. The addition of region and year, however, has little effect on the nonprofit wage advantage over forprofit workers. In results not shown, the separate entry of year and region into the model reveals that most of the reduction in the public differential is associated with region and little is associated with year. This suggests that public sector hospital workers tend to be more likely to live in lower paying regions of the country.

The final line of Table 4 includes only those workers who are located in certificate of need states. One possibility is that the rise of outpatient surgery centers and other specialty hospitals have affected the relative earnings of hospital workers by sector. That is, most of these tend to be for-profit establishments and are most likely to exist in states without certificate of need laws. The results in line 5 are quite similar to those in Line 4, however, suggesting that the changing nature of the hospital sector has had little impact on the public/private/not-for-profit wage differential. ${ }^{10}$

The results in Table 4 are informative since they provide insight into the source of wage differences between public sector and private for-profit and nonprofit workers. The table suggests that average wages between public and private sector workers are similar, despite public sector workers tending to hold higher levels of experience and education and public sector workers tending to locate in lower paying regions of the country. Likewise, the relatively large wage advantage of workers in nonprofit hospitals relative to for-profit hospitals is explained in large part by the higher levels of schooling and experience held by those workers in nonprofit hospitals. These results suggest that for-profit hospitals tend to attract workers with lower measured

\footnotetext{
${ }^{10}$ In results not shown, I estimate wage equations including CON and non-CON states and include a dummy variable for CON and interactions between CON and hospital sectors. While wages in CON states tend to be lower for practitioners (about $2 \%$ for RNs), the interaction terms are small and statistically insignificant for all the groups.
} 
Table 5 The effects of market concentration on the sectoral wage differentials

\begin{tabular}{llcll}
\hline & Public & Private non-profit & Log system hospitals & HHI \\
\hline All workers & $-0.025(0.009)$ & $0.015(0.006)$ & - & - \\
& $-0.024(0.009)$ & $0.016(0.067)$ & $0.013(0.003)$ & - \\
\multirow{2}{*}{ RNs } & $-0.020(0.011)$ & $0.029(0.007)$ & - & $-0.051(0.017)$ \\
& $-0.019(0.014)$ & $-0.004(0.009)$ & - & - \\
Other practitioners & $-0.019(0.014)$ & $-0.003(0.009)$ & $0.015(0.004)$ & - \\
& $-0.019(0.014)$ & $-0.003(0.009)$ & - & $-0.040(0.024)$ \\
Non-practitioners at least BA & $-0.038(0.021)$ & $0.023(0.021)$ & - & - \\
& $-0.038(0.021)$ & $0.023(0.014)$ & $0.005(0.006)$ & - \\
& $-0.038(0.021)$ & $0.023(0.014)$ & - & $-0.038(0.041)$ \\
Non-practitioners less than BA & $0.025(0.026)$ & $0.046(0.019)$ & - & - \\
& $0.026(0.026)$ & $0.049(0.019)$ & $0.022(0.008)$ & - \\
& $0.025(0.026)$ & $0.048(0.019)$ & - & $-0.097(0.054)$ \\
& $0.043(0.012)$ & $0.029(0.009)$ & - & - \\
& $0.043(0.012)$ & $0.030(0.009)$ & $0.010(0.004)$ & - \\
& $0.042(0.015)$ & $0.030(0.009)$ & - & $-0.076(0.027)$ \\
\hline
\end{tabular}

Data are from the January 2000 to March 2004 CPS ORG files. Hospital data are from the 2000 AHA's Annual Survey of Hospitals. The HHI is measured at the system level using average daily census.

skills and thus are paid lower wages, but that there is little unexplained wage difference between for-profit and nonprofit hospital workers. The one exception to this appears to be among nonpractitioners with a college degree where there remains a $6 \%$ differential even after accounting for measured skills and other variables.

In results not shown I estimate wage equations separately by year to examine if there is any discernable pattern in the public/private/not-for-profit wage differentials. Overall, the public wage disadvantage relative to for-profit hospitals remains relatively stable at about $2 \%$ or $3 \%$. Likewise the private for-profit/not-for-profit hospital wage differential, while showing some year-to-year variation, shows no discernable pattern and tends to be about $2 \%$ each year. Thus, if policy changes such as the BBA or other changes to Medicare reimbursement or the changes in the insurance industry have affected the earnings of hospital workers, they appear to have done so uniformly across the sectors and did not significantly impact the relative earnings of public sector or private not-for-profit hospital workers.

Table 5 shows results accounting for the effects of hospital output market structure. Data from the American Hospital Association's Annual Survey of Hospitals for the year 2000 are used to construct the Hirschman Herfindahl Index (HHI) using the metropolitan area as the market definition. ${ }^{11}$ Results here use the average daily census (at the level of the hospital system) in the construction of the HHI, but similar results are obtained when using other output measures (number of beds, patient days, or the number of RNs). Also shown are results using the $\log$ of the number of hospital systems in the market as an alternative to the HHI. Since the market is defined at the metropolitan area the sample is restricted to the January 2000 to the April 2004 CPS files due to a change in the definition of metropolitan areas in the CPS. Beginning in May 2004 the CPS began using new metropolitan area identifiers which corresponded to information from the 2000 Census. These

${ }^{11}$ Thanks to Joanne Spetz and Wendy Dyer for their assistance in accessing the AHA data and calculating the Herfindahl indices. 
new metro identifiers resulted in significant changes in the metropolitan area codes making it very difficult to construct time consistent codes. The AHA data has information on the previous Census codes, thus we restrict the analysis to be prior to May of 2004. Each worker in the CPS is assigned to one of about 200 metropolitan areas. $^{12}$ Workers not matched to a metropolitan area (generally cities with populations less than 100,000), are put into one of 50 rural state areas. Restricting the sample to only metropolitan areas and omitting the rural state groups yields similar results.

The table shows that controlling for market structure does little to the public/ private for-profit/not-for profit wage differentials. The table shows that as the number of hospitals in a market increases, the wages of hospital workers tends to increase. Note that it does not follow from this that there is evidence for monopsony power among hospitals. The number of hospitals is correlated with city size and wages are likely to increase with city size for reasons other than monopsony. ${ }^{13}$ Most relevant to this paper though is the effect of market structure variables on the hospital sector coefficients. When the market concentration variables are introduced to the model there is very little if any change to the public or private not-for-profit wage differentials. In results not shown, a model including interaction terms between market concentration and sector of employment is estimated. The coefficients on the interaction terms are always quite small and insignificant. ${ }^{14}$ Thus there is no evidence here that market concentration has any influence on the estimation of the sectoral wage differentials between hospital workers.

\section{Longitudinal Estimates of the Public/Nonprofit/for-Profit Wage Differentials in Hospitals}

The cross-sectional regressions find that for RNs once measurable characteristics are accounted for, there are few differences in wages across the three different sectors. Among other hospital workers, there is a small negative wage differential associated with public sector employment and a small positive differential associated with employment in a nonprofit hospital. This differential is largest among nonpractitioners with a college degree. If the included right-hand-side variables control completely for human capital and other determinants of earnings, or if those factors not included are uncorrelated with sector of employment, then the differentials could be interpreted as a wage premium for working in the private nonprofit sector. As discussed above, for-profit hospitals may face tighter financial pressure than private nonprofit hospitals and this could push wages down relative to the nonprofit sector.

\footnotetext{
${ }^{12}$ In cities made up of multiple metropolitan areas (New York City, Los Angeles, Dallas, etc.) the consolidated metropolitan area is used as the market definition.

${ }^{13}$ For discussion on this point see Hirsch and Schumacher (1995, 2005).

${ }^{14}$ Data from the 1993 AHA survey are also incorporated to construct the change in the HHI (and hospitals) between 1993 and 2000 and include this in these in the estimation in place of the level of market concentration. Again, the public and private not-for-profit wage differentials are not affected by the inclusion of these variables.
} 
These higher nonprofit wages may attract a higher quality of worker to the nonprofit hospital. The cross-sectional evidence is somewhat consistent with this type of selection, especially for nonpractitioners with a college degree. ${ }^{15}$ That the private nonprofit/for profit wage differential is largest for nonpractitioners with a college degree (who are more likely to be managers with more influence over wages) could potentially be a true rent. Roomkin and Weisbrod (1999), however, find higher compensation for executives in for-profit hospitals and also that for-profit hospitals are more likely to include bonuses and other contingent components of compensation that are not likely to be included in the wage variables collected in the CPS data. Since the CPS data utilized here only contain information on wages, however, it is possible that for profit hospitals offer larger non-wage compensation. Such things as stock options and other types of compensation in the for-profit sector could offset the $6 \%$ wage advantage for private nonprofits over for-profit hospitals.

Alternatively, nonprofit (and public) hospitals may attract workers who are more sympathetic to the cause of the hospital and may be willing to work for lower than normal wages. While there does not appear to be any evidence for this type of behavior within private nonprofit hospitals, it could be an explanation for the small negative wage differential associated with public sector employment. It could also be that public sector employment offers job amenities such as greater job security, more regular hours, or other nonwage attributes that workers are willing to pay for in the form of lower wages. On the other hand, it could be that private hospitals are able to attract a higher quality worker into their facilities due to better facilities, more stable financial conditions, more attractive clientele, etc. In this case the lower wage in the public sector would reflect ability or quality differences between the workers and would not be a true wage penalty for working in the public industry.

If there are omitted factors correlated with sector of employment and earnings, then the cross-sectional differentials will be biased estimates. Suppose the error term $\varepsilon$, can be broken down into two parts: $\varepsilon_{\mathrm{it}}=\chi_{\mathrm{i}}+e_{\mathrm{it}}$, where $\chi_{\mathrm{i}}$ is a person-specific component fixed over time, and $e_{i t}$ is a random, well behaved, component. If the omitted fixed effect is negatively correlated with public employment (e.g., less able workers are located in the public sector), then estimates of the public differential above are biased downward.

Letting the symbol $\Delta$ represent changes between adjacent years, a wage change equation will take the form (dropping the individual subscript $i$ ):

$$
\Delta \ln W_{d}=\sum_{j=1}^{J} \beta_{j} \Delta X_{j d}+\delta_{1}^{\prime} \Delta \text { Public }_{i d}+\delta_{2}^{\prime} \Delta \text { PrivateNP }_{i d}+\sum_{d=2}^{D} \phi_{d} \text { PERIODd }_{d}+\Delta_{e^{\prime} d},
$$

where $d$ indexes the time periods over which values are differenced, and Period $_{\mathrm{d}}$ are dummies for the periods 1996/1997 through 2001/2002 (with 1995/1996 the reference period). The major distinction between Eqs. 2 and 1 is that the effects owing to unmeasured skills fall out, potentially allowing for unbiased estimates of the quality-constant premium between sectors of employment. If the estimate of $\delta_{2}{ }^{\prime}$

\footnotetext{
${ }^{15}$ Holtman and Idson (1993) Find that for-profit nursing homes pay higher wages to their RNs than do not-for-profit nursing homes due to the former providing a higher overall level of quality.
} 
in Eq. 2 is similar to that of $\delta_{2}$ in Eq. 1, then this suggests that the wage differential associated with non-profit employment is a true wage differential due to either compensating differentials or to a true rent. If, however, the estimate of $\delta_{2}{ }^{\prime}$ goes to zero, then this implies the wage advantage estimated in Eq. 1 is due to workerspecific attributes not captured in the data. For Eq. 2 to provide unbiased measures of the public/nonprofit/for-profit wage differentials, sectoral switching is assumed to be exogenous and ability must be equally valued at the margin by employers in all sectors (Gibbons and Katz 1992) and within a year's time. ${ }^{16}$

The CPS is structured such that individuals are included in the survey for four consecutive months and are asked the earnings questions in the fourth month (when they are "outgoing"). They are then out of the sample for 8 months but then included for four more months and are asked the earnings questions in the final month. The analysis conducted thus far utilized these "outgoing" rotation groups to construct the sample of hospital workers. Given the construction of the survey, the same individual is included in the survey in the same month for consecutive years. That is, if an individual is outgoing for the first time in March of 2000, they will also be outgoing in March of 2001. Thus it is possible to create a sample containing information on the same individual for two consecutive years. The CPS contains household identification numbers and record line numbers, but not individual identifiers. Matched pairs are created by sorting separate files based household ID, year, age, gender, etc. Because the census re-interviews households in fixed locations, individuals whose household moves or who move out of a household during the year are not represented in the sample. ${ }^{17}$

Panel data are constructed from multiple 2-year panels from the CPS ORG files for $1995 / 1996$ through $2001 / 2002$ by matching individuals in the same month in consecutive years. Because measurement error is a particular concern with longitudinal analysis, those with industry, occupation or earnings allocated by the census (in either year) are deleted from the sample. The resulting panel data set for $1995 / 1996$ through 2001/2002 contains data on 7,986 hospital workers in the health care industry, 2,529 RNs, 1,476 other practitioners, 937 nonpractitioners with at least a college degree, and 3,044 nonpractitioners with less than a college degree. Table 6 displays movements by group as well as the average change in wage for each category. While there are still a small number of movers in absolute terms, one of the advantages of examining the health care industry is that there are a relatively large number of movers into and out of the public sector as compared to studies examining the economy as a whole. Of the 1,111 workers in the public sector in year $1,79.9 \%$ stay in the public sector, $12.6 \%$ move to the for-profit sector, and $7.5 \%$ move to the nonprofit sector. Of the 3,455 workers in the private for-profit sector in year one, $70.9 \%$ remain there, $3.2 \%$ move to the public sector and $25.8 \%$ move to the private not-for-profit sector. There are similar movements in the other

\footnotetext{
${ }^{16}$ The above specification forces the effects of joining and leaving sector to be symmetric. That is, it assumes that the gain (or loss) in wage to moving out of the public sector is equal to the loss (or gain) in wage to moving into the public sector. This assumption can be relaxed by including eight separate dummy variables for the nine categories of changes between years (public to for-profit, public to nonprofit, public to public, etc.). Small sample sizes, however, make estimates from this specification unreliable.

${ }^{17}$ For details on the construction of the 2-year panels, see Macpherson and Hirsch (1995).
} 


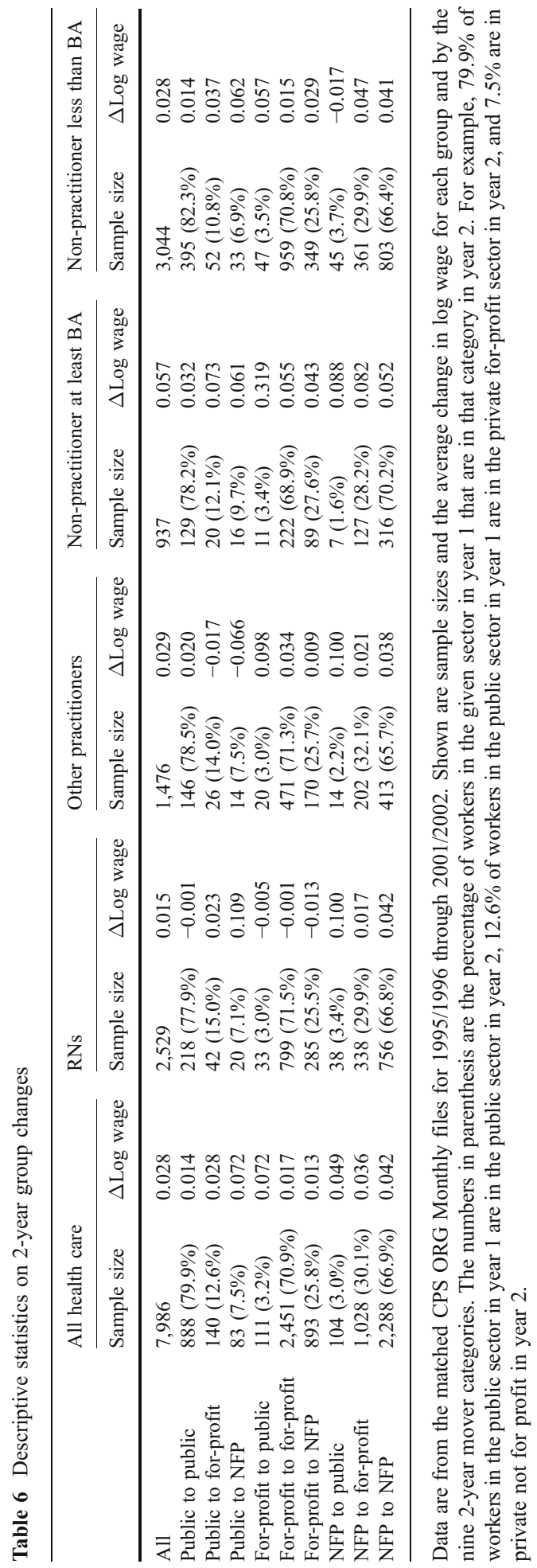


sectors and for the other groups of workers. There is much more movement between the for-profit and not-for-profit sectors than between the private and public sectors.

Overall, there is a $2.8 \%$ increase in wages for health care workers between years, consistent with the growth in wages over this period shown in Fig. 1. The wage change for RNs is $1.5 \%$ and for non-practitioners with a college degree it is $5.7 \%$. There does not appear to be a clear pattern in the wage changes among those who changed sectors of employment.

Average characteristics for movers vs. stayers by sector of origin are displayed in Table 7 for all healthcare workers and for RNs. For example, among all healthcare workers, those who stayed in the public sector in both years earned a real wage of $\$ 19.12$ (in the first year), and saw a $1.4 \%$ increase in the wage in the second year. Those who moved to the private sector started with a similar wage but experienced a larger increase in wage. Those who moved out of the private for-profit sector were already earning higher wages than those who stayed, but they experienced similar wage changes. Those who moved out of the public sector into private sector hospitals tended to be younger, were more likely to have a college degree, more likely to be female, married, and part-time, and less likely to be union members. Among RNs, those who left the public sector tended to be younger and earn lower wages, but experienced higher wage increases over the 2-year period. There does not appear to be much of a difference in wages or wage change for RNs moving and staying within the private sector.

Table 8 shows wage level regressions using the first year from the CPS matched panel data as well as wage change regressions. Cross-sectional results (for the pooled groups of workers) are similar to those estimated from the full CPS data. Wage change regressions, however, find little to no wage differences across all three sectors. The coefficient estimates relating to sector of employment are all very small and none of them are statistically significant.

These results suggest that there is no wage difference across the three sectors of employment in the health care industry. The small wage differentials found in the cross sectional results are not found in the wage change results. This suggests that these small differentials are not true wage premiums, but are due to unmeasured worker-specific factors. That is, the negative wage differential associated with public employment found in Table 3 is not due to these workers donating part of their earnings to the organization in support of its mission or to differences in job amenities, but may be explained by lower quality workers being attracted to the public sector. Among nonpractitioners where the cross-sectional wage differential with respect to nonprofit employment is largest, the coefficient associated with nonprofit employment decreases from 0.110 in the cross-sectional specification to (an insignificant) 0.048 in the wage change equation. This implies that to the extent that compensation to high skilled (as measured by schooling) workers nonprofit hospitals is higher than other sectors, it is due in large part to the selection of higher quality workers into that sector. ${ }^{18}$ The main story of Table 8 , however, appears to be

\footnotetext{
${ }^{18}$ In results not shown results are estimated excluding workers in the states of Texas and Florida where the acquisition of not-for-profit and public hospitals was substantial in the late 1990s. If a hospital transitions from not-for-profit to for-profit between years, it may take longer than one year for wages to adjust. Results are not affected, however, when these states are excluded.
} 


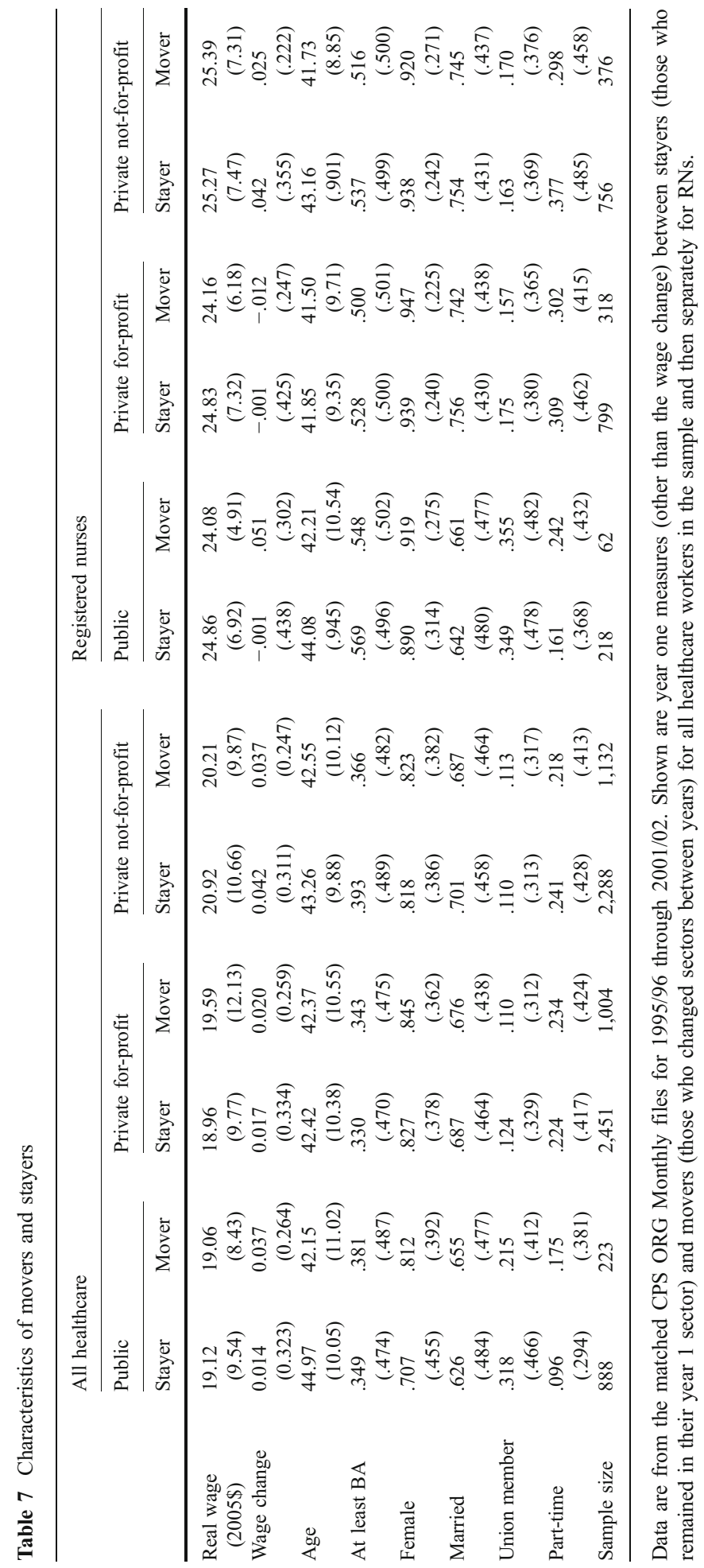




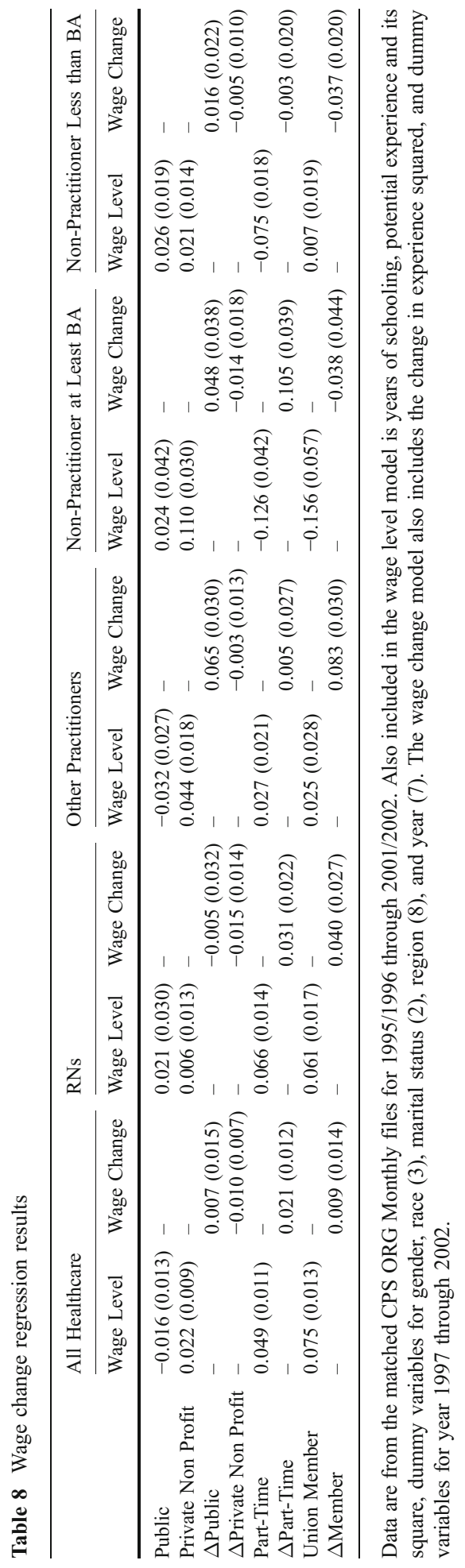


that there are few wage differences across the three types of hospitals. Alternatively, with such a small cross-sectional differential, only a small amount of measurement error in the CPS data would be required to push the coefficient estimates to zero.

Also shown in Table 8 are estimates of the part-time and union wage differentials. Note that the positive part-time differential for RNs in the cross-sectional analysis of about $6 \%$ is reduced to about $3 \%$ in the wage change analysis. This suggests that there is a true differential associated with part-time employment, and is consistent with part-time jobs being associated with differences in shift work. Similarly, the union differential for practitioners remains positive and significant through the wage change analysis.

\section{Conclusion}

This paper examines the role of the sector of employment in the earnings of workers in the health care industry. The results find that once personal characteristics are accounted for, workers in the public sector earn slightly lower wages than those in the other sectors of employment. Public sector workers are found to earn about $4 \%$ lower wages than private nonprofit workers, and about $2 \%$ less than private forprofit workers. RNs appear to be the exception to this as there are few wage differences across sectors. The labor market for RNs was quite competitive over this period and thus it is not too surprising that wages would equalize across sector.

Before adjusting for measurable characteristics workers in private nonprofit hospitals tend to earn about $9 \%$ higher wages than workers in other sectors of employment. Much of this difference is due to nonprofit hospitals attracting workers with higher levels of schooling and experience. Given the lack of a residual claimant in the nonprofit hospital, managers may have less incentive to hold wages down and this could lead to higher wages nonprofit hospitals relative to the other sectors. Assuming this occurs, however, we would expect workers to queue for these jobs, and nonprofit hospitals may be able to attract higher quality workers. To the extent that potential experience and degree attainment are correlated with quality, the evidence here is consistent with this type of sorting. The size of this difference, however, is relatively small.

Wage change analysis utilizing 2-year panels constructed from the CPS finds no significant differences between the groups. This suggests that the small public private wage differential is due to unmeasured ability, suggesting that lower quality workers are attracted to the public sector ${ }^{19}$. Alternatively, small sample sizes and potential measurement error in the longitudinal data could be biasing the wage change results towards zero. But given that even the cross-sectional differentials are quite small, the results here suggest that there are few differences across sector and are consistent with competitive wage setting behavior.

Previous research examining the public/private or for-profit/not-for-profit wage differentials has pointed out the need to compare similar worker doing similar jobs

${ }^{19}$ Or public hospitals may be concentrated in areas where lower quality workers are plentiful. 
across the different sectors of the labor market. The approach taken here is to examine workers within a narrow industry (hospitals) that are heavily represented by all three sectors of the economy. While it may be difficult to make inferences across other occupations based on these results, the findings suggest that, once worker and job characteristics are accounted for there is little difference in earnings between public sector, private for-profit, and private not-for-profit jobs. ${ }^{20}$

There is a large IO literature examining differences in the behavior of for-profit and not-for-profit hospitals. The results are somewhat mixed, but for the most part few differences are found in output, costs, efficiency, pricing, and provision of uncompensated care (Chakravarty et al. 2005). The results here are consistent with there being few differences in costs across hospital sectors. While there are small wage differences between workers across the three sectors, it appears that public, private for-profit, and private not-for-profit hospitals operate in the same labor markets.

\section{References}

Bazzoli GJ, Lindrooth RC, Hasnain-Wynia R, Needleman J (2004) The balanced budger act of 1997 and U.S. hospital operations. Inquiry 41(4):401-417

Belman D, Heywood JS (2004) Public wage differentials and the treatment of occupational differences. J Policy Anal Manag 23(1):135-152

Buerhaus PI, Staiger DO (1996) Managed care and the nurse workforce. JAMA 276(18):1487-1493

Chakravarty S, Gaynor M, Klepper S, Vogt WB (2005) Does the profit motive make Jack nimble? Ownership form and the evolution of the U.S. hospital industry. National Bureau of Economic Research, Working Paper 11705, October

Currie J, Farsi M, Bentley Macleod W (2005) Cut to the bone? Hospital takeovers and nurse employment contracts. Ind Labor Relat Rev 58(3):471-493

Easley D, O'Hara M (1983) The economic role of the nonprofit firm. Bell J Econ 14(2):531-538

Frank RG, Salkever DS (1994) Nonprofit organizations in the health sector. J Econ Perspect 8(4):129-144

Gibbons R, Katz LF (1992) Does unmeasured ability explain inter-industry wage differentials? Rev Econ Stud 59(3):515-535

Handy F, Katz E (1998) The wage differential between nonprofit institutions and corporations: getting more by paying less. J Comp Econ 26(2):246-261

Hatch J (2004) Employment in the public sector: two recessions' impact on jobs. Mon Labor Rev 127 (10):38-47

Hirsch BT (2005) Why do part-time workers earn less? The role of worker and job skills. Ind Labor Relat Rev 58(4):525-551

Hirsch BT, Schumacher EJ (1995) Monopsony power and relative wages in the labor market for nurses. J Health Econ 14(4):443-476

Hirsch BT, Schumacher EJ (1998) Union wages, rents, and skills in health care labor markets. J Labor Res XIX(1):1-23

Hirsch BT, Schumacher EJ (2004) Match bias in wage gap estimates due to earnings imputation. J Labor Econ 22(3):689-722

Hirsch BT, Schumacher EJ (2005) Classic or new monopsony? Searching for evidence in nursing labor markets. J Health Econ 24(5):969-989

\footnotetext{
${ }^{20}$ It is possible that for profit/public status may affect the wage of all health care workers, but mobility across hospital eliminates for-profit differentials within the hospital industry. If this were the case then the estimation here would not detect this differential as it would require comparing workers in and out of the hospital industry.
} 
Hirsch BT, Wachter ML, Gillula JW (1999) Postal service compensation and the comparability standard. Res Labor Econ 18:243-279

Hoerger TJ (1991) 'Profit' variability in for-profit and not-for-profit hospitals. J Health Econ 10(3):259289

Holtman AG, Idson TL (1993) Wage determination of registered nurses in proprietary and nonprofit nursing homes. J Hum Resour 28(1):55-79

Horwitz JR (2005) Does corporate ownership matter? Service provision in the hospital industry. NBER Working Paper \#11376, May

Lakdawalla D, Philipson T (1997) Nonprofit production and competition. Working Paper 6377, National Bureau of Economic Research, Cambridge, MA

Lakdawalla D, Philipson T (2006) The nonprofit sector and industry performance. J Public Econ 90(89):1681-1698

Lindrooth RC, Bazzoli GJ, Needleman J, Hasnain-Wynia R (2006) The effect of changes in hospital reimbursement on nurse staffing decisions at safety net and nonsafety net hospitals. Health Serv Res 41(3):701-720 Part I

Macpherson DA, Hirsch BT (1995) Wages and gender composition: why do women's jobs pay less? J Labor Econ 13(3):426-471

Moulton BR (1990) A reexamination of the federal-private wage differential in the United States. J Labor Econ 8(2):270-293

Roomkin MJ, Weisbrod BA (1999) Managerial compensation and incentives in for-profit and nonprofit hospitals. J Law Econ Organ 15(3):750-728

Rose-Ackerman S (1996) Altruism, nonprofits, and economic theory. J Econ Lit 34(2):701-728

Ruhm CJ, Borkoski C (2003) Compensation in the nonprofit sector. J Hum Resour 38(5):992-1021

Schumacher EJ (2001) The earnings and employment of nurses in an era of cost containment. Ind Labor Relat Rev 55(1):116-132

Schumacher EJ, Hirsch BT (1997) Compensating differentials and unmeasured ability in the labor market for nurses: why do hospitals pay more? Ind Labor Relat Rev 50(4):557-579

Sloan FA (2000) Not-for-profit ownership and hospital behavior. In: Culyer AJ, Newhouse JP (eds) Handbook of health economics. Elsevier Science B.V., New York, pp 1141-1174

Sloan FA, Steinwald B (1980) Hospital labor markets: analysis of wages and work force composition. D. C. Health-Lexington Books, Lexington, MA

Sullivan D (1989) Monopsony power in the market for nurses. J Law Econ 32 (2 (pt. 2):S135-S178

Zuckerman S, Bazzoli G, Davidoff A, LoSasso A (2001) How did safety-net hospitals cope in the 1990s. Health Aff 20(4):159-168 